\title{
Ocular hazards of nebulized bronchodilators
}

\author{
K.M. Mulpeter', J.B. Walsh', M. O'Connor'², F. O'Connell ${ }^{3}$ and C. Burke ${ }^{3}$ \\ ${ }^{1}$ Mercer's Institute for Research on Ageing, St James's Hospital, Dublin $8,{ }^{2}$ St James's Hospital, Dublin 8 , \\ and ${ }^{3}$ Department of Respiratory Medicine, James Connolly Memorial Hospital, Blanchardstown, \\ Dublin 15, Ireland
}

\begin{abstract}
Summary: Three cases of pupillary dilatation associated with the development of acute glaucoma, precipitated by the use of nebulized bronchodilators are described. We suggest measures to reduce the risk of this complication.
\end{abstract}

\section{Introduction}

Nebulized bronchodilators, both beta-agonists and anticholinergics are in common use both in hospital and in domicillary practice. The ocular hazards of these compounds, particularly ipratropium bromide in nebulized form, may be underestimated. The following 3 cases serve to illustrate the problem.

\section{Case 1}

A 75 year old woman was admitted with an infective exacerbation of chronic obstructive airways disease (COAD), and congestive cardiac failure. The patient wore reading glasses but had no other ocular problems. Initial treatment was with nebulized salbutamol $2.5 \mathrm{mg}$ and ipratropium bromide $0.25 \mathrm{mg} 6$ hourly by Hudson disposable aerosol face-mask, enalapril $2.5 \mathrm{mg}$ and frusemide $40 \mathrm{mg}$ daily, hydrocortisone $100 \mathrm{mg}$ intravenously (i.v.) 6 hourly, ceftizoxime $1 \mathrm{~g}$ i.v. twice daily. Five days after admission, her visual acuity deteriorated, and she could perceive light only. Both pupils were dilated, ovoid and non-reactive, and there was bilateral corneal oedema. Digital estimation suggested raised intra-ocular pressure, and a diagnosis of acute bilateral closed-angle glaucoma was made. Treatment was commenced with intravenous acetazolamide, and topical pilocarpine and betamethasone. The nebulized bronchodilators were stopped, and over the next 2 weeks, visual acuity improved to $6 / 12$ and $6 / 24$. Of note is the observation that ward staff had noted the face-mask displaced over the patient's forehead and eyes on several occasions.

Correspondence: K. Mulpeter, M.R.C.P.I., Department of Medicine for the Elderly, Crawley Hospital, West Green Drive, Crawley, West Sussex RH11 7DH, UK Accepted: 5 August 1991

\section{Case 2}

A 72 year old man with COAD was admitted to the intensive care unit following a cardiac arrest. Ten days after commencing nebulized salbutamol $2.5 \mathrm{mg}$ and ipratropium bromide $0.25 \mathrm{mg} 4$ times daily by face-mask, it was noted that both pupils were dilated, ovoid and non-reactive. Both eyes were stony hard with hazy corneae, consistent with a diagnosis of acute bilateral closed-angle glaucoma. The patient was semi-conscious and has not complained of pain. Other medications at the time were digoxin $0.25 \mathrm{mg}$ daily, verapamil $80 \mathrm{mg}$ 8 hourly, frusemide $40 \mathrm{mg}$ (i.v.) daily and cefotaxime $1 \mathrm{~g}$ (i.v.) 6 hourly. The nebulized ipratropium bromide was stopped and treatment was commenced with intravenous acetazolamide and topical pilocarpine. One week later, eye pressures were normal, the pupils were reactive and visual acuity was $6 / 12$ in both eyes.

\section{Case 3}

A 28 year old woman with a long history of severe asthma was admitted with an acute exacerbation. Maintenance medication on admission was inhaled fenoterol hydrobromide $90 \mu \mathrm{g}$ and ipratropium bromide $36 \mu \mathrm{g}$ per metered inhalation ( 2 inhalations 4 times daily), inhaled budesonide $400 \mu \mathrm{g}$ twice daily, inhaled nedocromil sodium $4 \mathrm{mg}$ 4 times daily, theophylline $300 \mathrm{mg} 3$ times daily, prednisolone $45 \mathrm{mg}$ daily, azathioprine $50 \mathrm{mg}$ 3 times daily, and nebulized ipratropium bromide $0.5 \mathrm{mg} 4$ times daily. The ipratropium bromide was increased to 6 times daily and the prednisolone increased to $60 \mathrm{mg}$ daily on admission, and ofloxacin $100 \mathrm{mg}$ twice daily was commenced. Nebulized beta-agonists were not administered because of previous adverse effects.

Nine days after admission the patient com- 
plained of headache and blurred vision, and a dilated and sluggishly reactive left pupil was noted. Computed tomographic brain scan and cerebrospinal fluid examination were normal and on stopping the ipratropium bromide, the headache and pupillary signs resolved.

\section{Discussion}

These patients demonstrate significant side effects of nebulized bronchodilator therapy. The diagnosis of glaucoma in the first 2 cases was based on the presence of hazy corneae, dilated ovoid nonreactive pupils and increased intra-ocular pressure assessed digitally. Tonometry was not performed acutely but the diagnosis was confirmed by a consultant ophthalmologist in both cases. Unlike inhaled bronchodilators, ${ }^{1,2}$ nebulized ipratropium bromide and salbutamol in combination have been shown to cause a rise in intra-ocular pressure. ${ }^{3}$ Topical absorption of the bronchodilators across the cornea is postulated to be responsible for this effect. Precipitation of acute closed-angle glaucoma by nebulized bronchodilators was first described in 1982, when ipratropium bromide was implicated. ${ }^{4}$ In a second case the patient received both salbutamol and ipratropium bromide. ${ }^{5}$ Nebulized salbutamol used alone has been implicated in one case. ${ }^{5}$ The manufacturers of ipratropium bromide (Boehringer Ingelheim) have received 4 reports of glaucoma precipitated by the use of the drug. A recent report described 5 cases of pupillary dilatation attributed to ipratropium bromide. ${ }^{6}$

In our opinion, the main agent implicated in precipitation of glaucoma by nebulized bronchodilators is ipratropium bromide due to the anticholinergic effect of the absorbed drug, although salbutamol may have a facilitative action by its effect on aqueous humor production.

Promp diagnosis of acute glaucoma is essential to prevent blindness, but a high index of suspicion may be necessary in patients with COAD, hypoxia, hypercapnia and impaired consciousness, such as our first 2 patients who had no pain whatsoever.

We suggest that clinicians should maintain a high index of suspicion for ocular complications of nebulized bronchodilators. Strict attention should be paid to ensure that face-masks are tight-fitting and correctly positioned to prevent topical absorption of nebulizer solution across the cornea. Administration of solution via a 'tube device' may decrease the risk of topical absorption further. Patients with a past history of glaucoma warrant particular attention, but susceptible patients with narrow anterior chambers may have no past history of glaucoma. Patients being commenced on domicillary nebulized bronchodilators should be warned about the possible risk of glaucoma, and about measures to minimize this risk. Furthermore, we would suggest that all wards should have a supply of acetazolamide and pilocarpine available for emergency treatment of glaucoma. Finally we note the manufacturer's warning which states that caution is advised in the use of nebulized ipratropium bromide in patients with a history of glaucoma. We suggest this warning is inadequate and should state that all patients should be considered at risk of developing glaucoma with the use of this agent in nebulized form.

\section{References}

1. Sheufler, C. Opthalmotonometry, pupil diameter and visual accommodation following repeated administration of Sch 1000 MDI in patients with glaucoma. Postgrad Med J 1975, 51 (Suppl 7): 132.

2. Thumm, H.W. Ophthalmic effects of high doses of Sch 1000 MDI in healthy volunteers and patients with glaucoma. Postgrad Med J 1975, 51 (Suppl 7): 132.

3. Karla, L. \& Bone, M.F. The effect of nebulised bronchodilator therapy on intraocular pressures in patients with glaucoma. Chest 1988, 93: 739-741.

4. Malawi, J.T., Robinson, G.M. \& Seneviratne, H. Ipratropium bromide induced angle closure glaucoma (letter). NZ Med J 1982, 95: 759.

5. Packe, G.E., Cayton, R. \& Mashoudi, N. Nebulised ipratropium bromide and salbutamol causing closed angle glaucoma (letter). Lancet 1984, ii: 691.

6. Roberts, T.E. Wide eyes and breathless. Br Med J 1989, 299: 1348. 